\title{
HUMANIZAÇÃO DA SAÚDE E INCLUSÃO SOCIAL NO ATENDIMENTO DE PESSOAS COM DEFICIÊNCIA FÍSICA
}

\author{
HUMANIZATION OF HEALTH AND SOCIAL INCLUSION IN CARING FOR PEOPLE WITH PHYSICAL \\ DISABILITIES
}

\section{HUMANIZACIÓN DE LA SALUD E INCLUSIÓN SOCIAL EN LA ATENCIÓN DE PERSONAS CON DEFICIENCIA FÍSICA}

\author{
Aline Missel $^{1}$ \\ Cassia Cinara da Costa ${ }^{2}$ \\ Gustavo Roese Sanfelice ${ }^{3}$
}

Resumo O objetivo foi investigar percepções e atuações de profissionais da área da saúde que atuam em instituições de reabilitação com pessoas portadoras de deficiência física, nos aspectos relacionados à inclusão social, humanização da saúde e formação acadêmica. Realizou-se uma pesquisa qualitativa descritiva, utilizando observações e entrevistas semiestruturadas como instrumentos de coleta de dados. Com base nos resultados, originaram-se três categorias: aspectos sociais do sujeito; atuação e conhecimento em relação à inclusão social e formação; e concepção de humanização da saúde. Foram observadas a complexidade da reabilitação de pessoas com deficiência física e a identificação de obstáculos que precisam ser transpostos, como dificuldades para o acesso adequado e precoce aos serviços do Sistema Único de Saúde; falta de efetividade e eficácia das políticas públicas e legislação em relação à saúde e à acessibilidade; e carência em capacitação sociocultural e humanizada dos profissionais envolvidos. Concluímos que o papel da formação acadêmica e o de políticas públicas efetivas relacionadas à saúde e à acessibilidade são fundamentais para a inclusão social de pessoas com deficiência física, pois trata-se de aspectos interligados, que necessitam de trabalho intersetorial para garantir assistência reabilitacional de qualidade.

Palavras-chave pessoas com deficiência; reabilitação; socialização; humanização da assistência.
Abstract The aim was to investigate the views and actions of health professionals working with people with physical disabilities at rehabilitation institutions with regard to social inclusion, the humanization of health, and academic training. A descriptive qualitative study was carried out using observations and semi-structured interviews as tools for data collection. Three categories originated from the results: The social aspects of the subject, expertise and knowledge on social inclusion and training, and the concept of humanization of health. We found the complexity of rehabilitating people with physical disabilities and to identify hurdles that need to be overcome, such as difficulties in early and adequate access to Unified Health System services; the lack of public policy and law effectiveness and efficiency with regard to health and accessibility, and a lack of sociocultural and humane training of the professionals involved. We concluded that the role played by academic training and effective public policies related to health and accessibility are fundamental to the social inclusion of people with disabilities because the process is related with interconnected aspects that require intersectoral work to ensure quality rehabilitation care.

Keywords people with disabilities; rehabilitation; socialization; humanization of assistance. 


\section{Introdução}

Estatísticas da Organização Mundial da Saúde (OMS) revelam que 1 bilhão de pessoas no mundo apresentam algum tipo de deficiência (Organização das Nações Unidas, 2011). No Brasil, segundo o censo demográfico de 2010, o número de pessoas com deficiência é de aproximadamente $23,9 \%$ da população. Deste percentual, 7\% são de pessoas com deficiência física (Instituto Brasileiro de Geografia e Estatística, 2010). Esses dados justificam a relevância de estudos em relação a práticas em saúde e inclusão social de pessoas com deficiência física.

A Classificação Internacional de Funcionalidade, Incapacidade e Saúde (CIF), aprovada em 2001 pela OMS, representa um dos grandes avanços na compreensão da deficiência física, levando em consideração a função e a estrutura corporal, atividades e participação, como também os fatores ambientais (Farias e Buchalla, 2005). A partir da CIF, os prognósticos (funcionalidades e incapacidades) dos indivíduos não são baseados somente nas patologias e/ou sequelas, mas também no contexto ambiental onde vivem, evitando, dessa forma, rótulos impostos pelos diagnósticos. Também representaram avanços a Convenção Internacional sobre os Direitos das Pessoas com Deficiência (Organização das Nações Unidas, 2006) e a Política Nacional de Saúde da Pessoa com Deficiência, que norteia o campo da saúde no SUS (Brasil, 2008).

A pessoa em processo de reabilitação física depara-se com questões e conflitos acerca de muitos aspectos de sua vida, incluindo as mudanças em seu corpo e todos os fatores sociais envolvidos. Segundo Le Breton (2011), o indivíduo é reduzido ao seu corpo e a como esse corpo é visto socialmente, uma vez que a existência humana significa mover-se corporalmente em determinado espaço e tempo. O autor assinala que, no sujeito com deficiência física, há uma sensação de que "o corpo o abandonou", e os profissionais da saúde especialistas em reabilitação têm como objetivo organizar essa fragmentação. Goffman (1988, p. 7) explica que tais profissionais são os primeiros a informar "a situação do indivíduo que está inabilitado para a aceitação social plena", em razão de marcas corporais que geram estereótipos e identidades sociais depreciativas.

De acordo com Douglas (1998), as práticas seletivas que estimulam ou desestimulam determinadas ações significam considerar a ordem social agindo sobre as "mentes individuais", ou seja, levando em consideração que o indivíduo está sob influência do entorno social. Pelo que foi exposto, o contexto de implicações, valores e relações entre pacientes e equipe profissional é o que serve de fundamento ou direcionamento para o trabalho adequado e de qualidade. A pessoa com deficiência física vive situações de incerteza em relação às suas próprias limitações. O mesmo ocorre com o profissional de saúde envolvido em sua reabilitação, pois tem de descobrir 
quais são as necessidades individuais relevantes, procurando sempre valorizar as potencialidades do indivíduo.

Em todos os envolvidos na reabilitação de pessoas com deficiência física, percebe-se que há dificuldades em entendê-las como sujeitos não fragmentados por limitações e incapacidades. São reconhecidos como indivíduos atuantes no meio social em que vivem e não somente como 'um corpo a ser consertado'. Nesse sentido, não há como deixar de abordar a humanização na área da saúde em seus meios e fins relacionados a valores e à felicidade humana e sensações de bem-estar (Ayres, 2005).

Na tentativa de compreender as atuações dos profissionais de saúde quanto à atenção humanizada e à inclusão social de pessoas com deficiência física, desenvolveu-se a pesquisa aqui apresentada, que consistiu em investigar as percepções e as atuações de profissionais da área da saúde em instituições de reabilitação com pessoas portadoras de deficiência física, nos aspectos relacionados à inclusão social, humanização da saúde e formação acadêmica. A medicina, a fisioterapia e a fonoaudiologia abrangeram as profissões selecionadas para fazer parte da pesquisa por estarem vinculadas diretamente com a reabilitação dos pacientes nos contextos investigados. A pesquisa utilizou discursos, ações diárias e da convivência para verificar como esses profissionais de saúde entendiam e percebiam as questões relacionadas à inclusão social e à atenção humanizada, bem como para identificar as contribuições da formação acadêmica na aquisição de conhecimentos nessas temáticas.

Pelo fato de existirem relações intensas entre a rotina diária da pessoa com deficiência física e o processo de reabilitação é que se justificou a importância de se averiguar se havia a inserção de aspectos relacionados à inclusão social nesse processo. Goffman (1988) explica que a rotina diária é o conceito-chave por mostrar as diversas relações sociais que o indivíduo desenvolve e das quais participa. Por sua vez, Le Breton (2011) considera que a vida cotidiana é a matéria-prima a partir da qual se constrói a vida social.

Assim, parece indiscutível que os profissionais da saúde não devem restringir suas atuações às 'quatro paredes' da instituição, mas sim identificar a contribuição e a repercussão do trabalho de reabilitação no entorno social da pessoa com deficiência física.

\section{Metodologia}

A pesquisa caracterizou-se como qualitativa-descritiva. O campo de estudo limitou-se ao município de Porto Alegre, capital do estado do Rio Grande do Sul, em duas instituições de reabilitação: IRl e IR2. O período de coleta de dados foi de 7 de junho a 20 de agosto de 2013. 
Participaram da pesquisa profissionais da área da saúde que atuavam nessas instituições e que já tivessem concluído a graduação: um médico, um fisioterapeuta e um fonoaudiólogo de cada instituição. Os critérios de inclusão das instituições foram os seguintes: instituição que trabalhasse com reabilitação de crianças e jovens há mais de quatro anos e instituições com equipes multiprofissionais. E os critérios de inclusão dos entrevistados: ser profissional da saúde; ser responsável pelos atendimentos; ter mais tempo de atuação na instituição.

Para a coleta de dados, um dos instrumentos utilizados foi uma entrevista semiestruturada aplicada individualmente a cada profissional informalmente, baseada em um roteiro básico de perguntas orientadas por pressupostos e objetivos relacionados com o tema da pesquisa.

Também foram realizadas observações das atuações desses profissionais em atendimentos a pacientes com deficiência física, cuja descrição se fez por meio de um diário de campo baseado em um roteiro, levando em consideração situações relacionadas à inclusão social e ao atendimento humanizado, como as orientações e, se houvesse, os questionamentos e/ou abordagens efetuadas sobre essas temáticas. Observaram-se quatro atendimentos de cada profissional para pacientes que apresentassem algum tipo de deficiência física, associada ou não à deficiência intelectual, não importando a idade e o sexo. A observação foi individual e não participante. O pesquisador fez contato com o profissional e o paciente em atendimento, mas não participou ativamente da consulta (Ferreira, 2011).

A fim de manter o sigilo dos entrevistados, os autores adotaram siglas médico, ME; fonoaudiólogo, FO; e fisioterapeuta, FI - e números para identificá-los.

A pesquisa foi encaminhada e aprovada pelo Comitê de Ética em Pesquisa da Universidade Feevale, a fim de análise dos aspectos éticos envolvidos (protocolo n. 15725913.8.0000.5348). Cada participante manifestou formalmente seu interesse em participar do estudo, por meio da assinatura do termo de consentimento livre e esclarecido.

\section{Resultados e discussão}

As características acadêmicas dos profissionais envolvidos na pesquisa estão detalhadas no quadro 1, permitindo uma visão resumida do perfil acadêmico desses profissionais de saúde. 
Quadro 1

\begin{tabular}{|c|c|c|}
\hline \multicolumn{3}{|l|}{ Perfil acadêmico dos profissionais } \\
\hline Médica: ME1 & Fisioterapeuta: FI1 & Fonoaudióloga:FO1 \\
\hline Faculdade: Fundação de Ciências da Saúde & Faculdade: Universidade Feevale & Faculdade: Centro Universitário \\
\hline Ano de conclusão da graduação: 1984 & Ano de conclusão da graduação: 1992 & Metodista (IPA/Porto Alegre) \\
\hline \multirow[t]{2}{*}{ Especialização: pediatria e UTI pediátrica } & Especialização: neurologia & Ano de conclusão da graduação: 2005 \\
\hline & Curso de extensão: conceito Bobath & Especialização: não \\
\hline Médica: ME2 & básico e avançado/RPG/Kabat & Curso de extensão: conceito Bobath \\
\hline \multicolumn{3}{|l|}{ Faculdade: Universidade de Passo Fundo } \\
\hline Ano de conclusão da graduação: 1996 & Fisioterapeuta: $\mathrm{FI} 2$ & Fonoaudióloga:FO2 \\
\hline Especialização: psiquiatria/psiquiatria da & Faculdade: Universidade Feevale & Faculdade: Centro Universitário \\
\hline \multirow[t]{4}{*}{ infância e adolescência } & Ano de conclusão da graduação: 2010 & Metodista (IPA/Porto Alegre) \\
\hline & Especialização: geriatria e geronto- & Ano de conclusão da graduação: 2005 \\
\hline & logia/mestrando em pneumologia & Especialização:gestão de atenção à saúde \\
\hline & & do idoso/mestrando em neurociência \\
\hline
\end{tabular}

Fonte: Os autores.

Nota: ME: Médico; FI: Fisioterapeuta; FO: Fonoaudiólogo; 1: IR1; 2: IR2.

O quadro 2 apresenta a distribuição das observações realizadas durante o período de coleta de dados, separadas por: data do atendimento observado, idade e diagnóstico médico do paciente e profissional responsável pelo atendimento.

Quadro 2

\begin{tabular}{|ccccc|}
\hline \multicolumn{3}{|c|}{ Identificações e peculiaridades das observações } & & \\
\hline Observação & Data & Idade & Diagnóstico médico & Profissional \\
O1 & $07 / 06 / 2013$ & 7 anos & Paralisia cerebral & ME1 \\
O2 & $07 / 06 / 2013$ & 5 anos & Paralisia cerebral & ME1 \\
O3 & $10 / 06 / 2013$ & 5 anos & Distrofia de Duchene & FI1 \\
O4 & $10 / 06 / 2013$ & 15 anos & Paralisia cerebral & Fl1 \\
O5 & $12 / 06 / 2013$ & 12 anos & Paralisia cerebral & FO1 \\
O6 & $12 / 06 / 2013$ & 16 anos & Paralisia cerebral & FO1 \\
O7 & $18 / 06 / 2013$ & 7 anos & Paralisia cerebral & FO1 \\
O8 & $18 / 06 / 2013$ & 17 anos & Mielomeningocele & Fl1 \\
O9 & $18 / 06 / 2013$ & 8 anos & Paralisia cerebral & FO1 \\
O10 & $25 / 06 / 2013$ & 13 anos & Paralisia cerebral & ME1 \\
O11 & $25 / 06 / 2013$ & 6 anos & Paralisia cerebral & ME1 \\
O12 & $25 / 06 / 2013$ & 13 anos & Paralisia cerebral & Fl \\
\hline
\end{tabular}

continua > 
Continuação - Quadro 2

\begin{tabular}{|ccccc|}
\hline \multicolumn{3}{|c|}{ Identificações e peculiaridades das observações } & & \\
\hline Observação & Data & Idade & Diagnóstico médico & Profissional \\
O13 & $16 / 07 / 2013$ & 3 anos & Atraso no DNPM ${ }^{4}$ & ME2 \\
O14 & $16 / 07 / 2013$ & 6 anos & Paralisia cerebral & ME2 \\
O15 & $16 / 07 / 2013$ & 7 anos & Paralisia cerebral & ME2 \\
O16 & $23 / 07 / 2013$ & 18 anos & Paralisia cerebral & FI2 \\
O17 & $23 / 07 / 2013$ & 16 anos & Paralisia cerebral & Fl2 \\
O18 & $23 / 07 / 2013$ & 14 anos & Paralisia cerebral & Fl2 \\
O19 & $30 / 07 / 2013$ & 7 anos & Atraso no DNPM & FO2 \\
O20 & $30 / 07 / 2013$ & 5 anos & Paralisia cerebral & FO2 \\
O21 & $30 / 07 / 2013$ & 13 anos & Paralisia cerebral & ME2 \\
O22 & $20 / 08 / 2013$ & 15 anos & Paralisia cerebral & FO2 \\
O23 & $20 / 08 / 2013$ & 15 anos & Paralisia cerebral & FO2 \\
O24 & $20 / 08 / 2013$ & 4 anos & Paralisia cerebral & Fl2 \\
\hline
\end{tabular}

Fonte: Os autores.

Nota 1: O: Observação; ME: Médico; FI: Fisioterapeuta; FO: Fonoaudiólogo.

Nota 2: DNPM: Desenvolvimento neuropsicomotor.

Para a análise dos dados, utilizou-se a análise de conteúdo de Bardin (2011).

Na etapa do tratamento dos resultados, realizaram-se categorizações não apriorísticas, selecionadas após as entrevistas e as observações, de acordo com o material obtido e explorado, baseadas nos conhecimentos teóricos, experiências e sensibilidade do pesquisador (Campos, 2004).

Os dados coletados por meio dos discursos dos profissionais de saúde e dos elementos produzidos no meio em que atuavam foram analisados pela técnica de triangulação de dados, caracterizada pela análise dos dados coletados de diferentes fontes (Duarte, 2009).

$\mathrm{Na}$ interpretação das informações, foram estabelecidas, previamente, três descritas a seguir:

Aspectos sociais do sujeito. A reabilitação é a assistência à saúde das pessoas com deficiência física, realizada com o objetivo de desenvolver o nível máximo de suas capacidades funcionais do ponto de vista físico, sensorial, intelectual, psíquico ou social, com consequente qualidade de vida, independência e participação na vida comunitária.

Percebe-se a importância de estímulos adequados e do meio ambiente para o desenvolvimento físico, tornando as experiências favoráveis para a interação das regiões cerebrais e para a melhor propagação de habilidades perceptuais, motoras, cognitivas e sociais. A prática e a experiência são capazes de organizar/reorganizar os mapas corticais, contribuindo para aquisições motoras funcionais (Simões, 2008). 
Os profissionais citaram com destaque a importância de se conhecer a família do sujeito em processo de reabilitação, incluindo todo o seu contexto sociocultural. Demonstraram, também, que as relações familiares e dos profissionais de saúde com o sujeito com deficiência interferem diretamente nos resultados dos tratamentos propostos. Concordaram com as fragilidades nessas relações e a importância do profissional da área da saúde em orientá-los e esclarecê-los sobre aspectos legais, afetivos e de cuidados com a saúde, conforme os relatos a seguir:

Os fatores sociais vão influenciar em tudo nos atendimentos, de como falar, como orientar algumas questões, verificar juntamente com o setor da assistência social o que essa família está precisando, as questões familiares (FO2).

É importante ter uma ideia dos aspectos socioculturais do paciente, pra poder entender como funciona a família, que aspectos que podem contribuir pra boa aderência ao tratamento, se procuram ter uma ideia do paciente como um todo (ME2).

Muitos ficam isolados somente em casa com a família e só vêm pra cá. A fisioterapia, em função das demandas e juntamente com o setor de psicologia, acaba tendo que intervir na família, trazendo a família (FI2).

Em primeiro lugar, a relação da família com a criança, conhecer a família, a sua casa, moradia, acessibilidade, os contatos, gestos de carinho (se houver), se esses gestos e atitudes são verdadeiros, se o que está diante de nós realmente acontece em casa, as relações familiares, atenção, se reflete em casa o que presenciamos aqui na instituição (FIl).

Temos que compreender melhor o contexto do paciente, porque podemos estar exigindo do paciente algo que ele não pode nos dar (...) até para saber o que podemos cobrar e exigir de retorno (...) (ME1).

Os profissionais FIl e MEl mencionaram a importância dos aspectos familiares para o processo de reabilitação, mas não foram observadas tais ações durante os atendimentos, aparecendo uma contradição entre o que foi citado nas entrevistas e a atuação dos profissionais.

A importância de se conhecer a estrutura familiar deve-se ao fato da contribuição essencial para a adaptação da criança com deficiência física. Muitas vezes, o desajustamento da criança está relacionado com o modo como a família lida com a situação; o isolamento da família torna-se acontecimento frequente, que pode deixar o sujeito mais vulnerável e suscetível às situações de exclusão social. Pelo fato de as instituições pesquisadas 
terem crianças como público-alvo, é pertinente abordar e discutir as relações nessa faixa etária, entender a infância geográfica e historicamente, e não como uma etapa natural da vida. Implica trazer para o debate questões relativas à família e aos vínculos existentes.

Sirota (2001, p. 8) indaga: "um pequeno sujeito ou um pequeno objeto?" questionamento que traz à tona os modelos de intervenção para a infância em termos médicos e terapêuticos. A infância é compreendida por um sistema geral de carências e de fragmentações. Esta fase, associada à deficiência física, se torna mais complexa pelo fato de haver necessidade de procedimentos médicos e terapêuticos constantes, possíveis hospitalizações e agravamentos de sua condição física.

Os profissionais FO1, FO2, FI1, FI2 e ME2 citaram também a importância de se conhecerem as características da moradia e as questões de acessibilidade de seus pacientes, que, consequentemente, interferem nas possibilidades de se vivenciarem experiências diferentes.

O local de moradia pra nós é importante, porque nos dá a possibilidade se tem acesso ou não, a possibilidade dele de sair de casa, de vivenciar experiências diferentes, onde o transporte pega e traz pra cá (FO1).

$\mathrm{Na}$ casa, se tem espaço para a cadeira de rodas, se for o caso, como essa criança se alimenta, posição, são muitos fatores, por isso é importante conhecer do paciente. Tudo o que acontece com ele fora daqui vai refletir diretamente nos resultados do tratamento fisioterapêutico (FIl).

(...) se essa criança não tem roupa, no inverno está passando frio, eu não tenho como atender bem essa criança, então é impossível eu não ficar preocupada com o meio externo dela, porque vai interferir na reabilitação (FO1).

Os profissionais FO1 e FO2 demonstraram, durante os atendimentos, a inserção dos fatores e também de moradia, como tipo, local, móveis e utensílios pessoais utilizados. Nas entrevistas, eles não citaram escola, mercado de trabalho e lazer, mas introduziram, constantemente, as atividades realizadas pelo paciente no seu dia a dia, dentro do ambiente de atendimento, inclusive detalhes como: cores, forma-tos, utilização e valores pessoais. Esses profissionais disseram que, quando era utilizado o ambiente do paciente, o processo de aprendizagem e desenvolvimento da linguagem era muito mais significativo e efetivo.

Segundo França e colaboradores (2004), a linguagem é exercida por meio de uma função superior do cérebro. Seu desenvolvimento depende de uma estrutura anatomofuncional geneticamente determinada e do estímulo verbal dado pelo meio. Não basta desenvolver a habilidade; é preciso que esta 
seja encadeada em um contexto de significação, no qual a pessoa com deficiência possa construir um raciocínio flexível, no sentido de fazer uso dessa habilidade como instrumento inserido no seu cotidiano.

A plasticidade neuronal é um processo em que a área lesada do cérebro pode ser substituída por uma área próxima. Quanto mais cedo for realizado o diagnóstico da patologia, maior é a capacidade desse mecanismo. Mas só será possível se a criança receber estímulos e trabalhos terapêuticos adequados (Pupo Filho, 2003).

Percebe-se a interferência dos estímulos ambientais para o desenvolvimento motor e linguístico, inclusive determinando a arquitetura e a fisiologia cerebral. O profissional envolvido no processo de reabilitação deve ter consciência dessa interferência para selecionar e conduzir os tratamentos/terapias.

Atuação e conhecimentos em relação à inclusão social e formação. Pesquisa realizada por Simões (2008) analisou a assistência oferecida às crianças com deficiências motoras em um centro de referência do SUS, em Salvador, na Bahia, por meio de depoimentos de profissionais de saúde sobre o conceito de reabilitação, e constatou que as respostas foram marcadas por divergências e diferentes compreensões, condizentes com o que se encontra na literatura. Em relação à inclusão social, salientou-se a falta de interdisciplinaridade entre os profissionais que atuavam no processo de reabilitação, escolas e serviços que ofereciam esportes ou cursos profissionalizantes, a fim de trabalhar outras competências e estimular o convívio social com suas capacidades máximas alcançadas, uma vez que esse é o principal objetivo da reabilitação. Os resultados da pesquisa sugeriram uma avaliação sobre as diretrizes curriculares dos cursos de nível universitário e a fragilidade das discussões sobre inclusão social na formação acadêmica dos profissionais da área da saúde (Simões, 2008).

Amorim, Moreira e Carraro (2001) chamam a atenção para o paradigma predominante na formação dos profissionais de saúde voltado para o modelo biológico, que dificulta a visão do indivíduo como um ser integral e interfere na compreensão do processo saúde e doença. Os autores sugerem revisão nos programas de formação dos profissionais de saúde, ressaltando que não se pode mais aceitar o bom desempenho técnico sem que ele esteja vinculado à cidadania e à ampla visão da realidade no contexto em que se atuará. Para Vilela e Mendes (2003), é fundamental que a universidade tenha responsabilidade social na formação dos seus alunos, assim como trabalhe os conceitos de equidade, acesso universal e qualidade no atendimento.

Nessa categoria, estima-se discutir conhecimentos, atuações e percepções dos profissionais sobre inclusão social e explicitar, ao se partir dos discursos coletados, as visões sobre suas formações acadêmicas em relação a essa temática. 
No questionamento sobre a inclusão social como atribuição da profissão, a profissional MEl comentou: “Eu não sou proativa, no sentido de melhorias, tanto de saúde quanto no todo"; e acentuou que não considerava uma atribuição de sua profissão: “A minha profissão já tem muitas atribuições". Em contradição, afirmou, ao ser indagada sobre a sua percepção do conceito de saúde, que "as pessoas que são ativas socialmente ficam menos doentes". A mesma profissional discordou das facilitações do meio para a inclusão social e disse que essas conquistas dependiam de características individuais. Em relação ao mercado de trabalho, questionou a inclusão de pessoas com deficiência física:

Tem muito desemprego, e aí você vai empregar uma pessoa que tem mais dificuldade que a outra, em função de uma deficiência?

Nesse sentido, para Pereira e colaboradores (2011), a acessibilidade é um direito e uma questão fundamental na vida das pessoas com deficiência física, o que resulta na construção de valores individuais e sociais, eliminando obstáculos e possibilitando a comunicação com o mundo. Os autores afirmam que a acessibilidade gera o direito de interagir com o meio, com o exercício do direito da cidadania e do direito de ir e vir. A falta de acessibilidade leva as pessoas à margem da sociedade, contribuindo para a exclusão social.

No campo da saúde, influenciado pelo sistema capitalista, há o direcionamento para que as pessoas sejam reduzidas à sua objetividade. A necessidade de estudos relacionados às atuações dos profissionais de saúde está vinculada às mudanças nos setores de perda de autonomia, assalariamento, condições de trabalho, flexibilização das relações de trabalho, incorporação tecnológica e especialização (Abrahão, Martins e Geisler, 2008). Desequilíbrios nesses fatores têm dificultado a gestão do mais complexo insumo do setor, os recursos humanos, agindo sobre sua dinâmica, formação, estrutura ocupacional e mercado de trabalho, fortemente influenciados pela lógica econômica da produção de bens e serviços de saúde (Abrahão, Martins e Geisler, 2008).

Em relação à inclusão de pessoas com deficiência física no mercado de trabalho, os profissionais FOl e FI2 afirmaram que é um percurso com muitos obstáculos, mas que é preciso interesse e capacitação das pessoas envolvidas para adaptar os ambientes e selecionar adequadamente as funções.

O profissional FOl comentou em relação à Lei de Cotas: ${ }^{5}$

Vejo como todo o resto da sociedade, muita hipocrisia, dá uma vaga porque é obrigado a dar, porque ninguém procura uma pessoa portadora de deficiência para dar um emprego.

Nas atividades de lazer, os profissionais FO1, FO2 e FI2 retomaram as questões de acessibilidade, considerando de extrema importância suas atuações 
para estimular e orientar nessas questões. Tal postura foi verificada nos seus discursos e nas observações de seus atendimentos. Os profissionais disseram que a situação era muito complexa e excedia as ações executadas pela instituição de reabilitação, como relatou FOl:

Claro que dentro das possibilidades, agora quando você vê uma criança, uma família, que mora longe, que tem dificuldades de pegar um ônibus para ir a qualquer lugar, com uma rua esburacada que não tem como andar com a cadeira de rodas, me desculpe, mas não tem como. (...) há dois anos o Demab [Departamento Municipal de Habitação] deu casas adaptadas. Uma das famílias estava brigando para trocar de casa em função de traficantes, era uma mãe sozinha com uma criança especial, aí eu vou dizer pra essa mãe sair um pouco de casa com seu filho, e se saísse de casa o traficante tomava conta. Orientar? Orientamos, mas é complicado porque não depende só da gente.

O profissional FOl não considerou a promoção de inclusão social como uma atribuição de sua profissão, mas explicou que não tinha como dissociar a inclusão social dos atendimentos fonoaudiológicos:

Como é que tu vais desenvolver uma linguagem de um paciente se não conhecer os aspectos sociais e culturais dessa família? Não adianta tu ensinar [sic] uma coisa que dentro de casa não é utilizada.

Já os profissionais FI2 e FO2 responderam que consideravam a promoção de inclusão social, em seus atendimentos, uma atribuição da profissão, e na prática foi observado que a aplicavam.

Eu trabalho com eles a socialização, não ficar somente na fisioterapia. A parte que mais vejo é a socialização, não somente o paciente vir pra cá para atendimento fisioterapêutico. Muitos dos meus pacientes eu participo da socialização aqui mesmo na instituição, com oficinas. Aqui dentro da instituição se trabalham paralelo a fisioterapia e a socialização (FI2).

Nos atendimentos observados do profissional FI2, realizaram-se atividades que exigiam movimentos funcionais e aplicados para o dia a dia do sujeito. Como presenciado na observação do atendimento O17, em que o paciente apresentava como sequela uma hemiparesia à direita (alteração de tônus muscular resultando em um padrão flexor de membro superior, que esteticamente torna o membro 'encolhido' e 'deformado' em comparação com o outro membro superior), o FI2 introduziu no atendimento a utilização de pulseiras, relógios e utensílios com o intuito de enfeitar o punho e o antebraço do membro afetado, sendo orientações associadas aos exercícios 
fisioterapêuticos. O paciente chegava ao atendimento mostrando o membro afetado ao profissional, com gestos voluntários, e irradiando satisfação destacava os enfeites que escolhera para utilizar naquele respectivo dia. Segundo o FI2, no início do tratamento fisioterapêutico o paciente escondia todo o membro afetado com blusas de mangas compridas, intensificando o padrão da lesão e gerando um aumento das deformidades articulares.

Em relação à comunicação adequada do diagnóstico de uma deficiência física, torna-se essencial a discussão sobre a humanização no âmbito da saúde. Quando o profissional olha globalmente seu paciente, atua de forma humanizada, preocupando-se com o impacto das informações na família e no paciente. Por se tratar de um momento extremamente importante para a manutenção posterior do tratamento e para o estabelecimento do vínculo família-paciente-equipe de saúde, é necessário que a formação profissional na área da saúde contemple a visão global do indivíduo.

Quando indagado sobre o ato de dar a notícia da deficiência física, o profissional MEl explicou que, no seu caso, atuante em UTI pediátrica, a prioridade é salvar a vida da criança, e se torna rotineiro amenizar as notícias ruins. Mas desabafou:

(...) ficamos chateados, porque tu dás a notícia que salvou a vida do filho deles e eles estão preocupados com a aparência física.

Em relação ao discurso, Ribeiro (2011, p. 828) afirma que a abordagem médica atual faz o possível para afastar a morte, ressaltando que morrer "é mais do que falência múltipla de órgãos, parada cardiorrespiratória ou morte do tecido encefálico": é um contexto físico, emocional, cultural e espiritual. O autor usa o termo "morrer curado" (Ribeiro, 2011, p. 828) quando pacientes curados de determinadas patologias orgânicas encontram-se sujeitos a uma 'morte' social, emocional ou espiritual.

Na observação do atendimento O13-ME2, o profissional questionou os pais sobre exames e avaliações da especialidade da neurologia, pois precisava entender melhor o diagnóstico da criança. A mãe respondeu que não conhecia o diagnóstico do seu filho e que o neurologista do posto de saúde que o encaminhara para a instituição de reabilitação somente havia explicado: “O cérebro do teu filho está atrofiado e não tem mais o que fazer!" O profissional ME2 ficou insatisfeito com a atitude do seu colega e disse que é de suma importância conhecer o diagnóstico correto, com o intuito de elaborar/prescrever o(s) tratamento(s) adequado(s).

Demonstrou-se que a relação médico-paciente está intimamente ligada às relações de poder, em que os médicos colocam-se em uma posição de autoridade e, muitas vezes, levam em consideração somente a sua visão da situação. Nesse sentido, também verificou-se durante as observações dos 
atendimentos do MEl a explícita visão unilateral do profissional, em que a presença da pesquisadora foi somente notificada aos responsáveis pelos pacientes; não houve momentos explicativos e de pedido de permissão para a presença da pesquisadora no ambiente do atendimento.

Estudo realizado por Goulart e Chiari (2010), com o objetivo de avaliar a relação médico-paciente, demonstrou que 14 pacientes (de uma amostra de 15) manifestaram-se insatisfeitos com as explicações fornecidas pelos médicos. Os autores explicam que é uma relação complexa, em que se deve ter como base a confiança no profissional e o respeito de ambas as partes, na tentativa de se colocar no lugar do outro.

Em consenso, os profissionais citaram que não receberam informações durante as suas formações acadêmicas, tanto teórica como prática, sobre inclusão social e atenção humanizada - com uma ressalva do FI2, que declarou que obteve conhecimentos nessas temáticas, mas os considerava insuficientes para sua atuação profissional. Durante a sua prática, foi observado que esses fatores estavam presentes constantemente.

Em relação aos anos das conclusões dos cursos dos profissionais FOl e FO2, em 2005, e do profissional FI2, em 2010, consideradas recentes, tais deficiências na formação tornavam preocupante a situação, uma vez que que o processo de formação profissional deve ser uma construção baseada no desenvolvimento de conhecimentos, ideias e valores determinados não apenas pelo setor acadêmico, mas econômicos, políticos, sociais e culturais (Goulart e Chiari, 2010). Cabe aos professores responsáveis pela formação dos profissionais da área da saúde apropriar-se de tais conhecimentos, mostrando, na prática, possibilidades diferentes daquelas historicamente estabelecidas pelas raízes biomédicas (Goulart e Chiari, 2010).

Segundo o profissional MEl, na época de sua formação, em 1984, "não se falava em inclusão social fora ou dentro das universidades", mas o profissional FOl destacou e criticou, com veemência, a sua formação, por não apresentar aprendizagens nesses aspectos:

(...) a teoria é muito bonita, você tem uma restrição com um paciente para ingerir líquidos, e aí você vai dizer para uma mãe: você não vai dar água pro seu filho! Você não tem o espessante, ${ }^{6}$ um calor do inferno, e a mãe não vai dar água! Isso é uma questão básica que a faculdade não te dá. Muitas vezes você não consegue fazer o que a faculdade te ensina, 'as receitas de bolo', e aí tu tens que inventar coisas para suprir essas necessidades (...) e dentro dessa linha de raciocínio a faculdade não contribui, tu aprendes o estático e não o dinâmico, porque o atendimento é dinâmico.

O profissional FOl afirmou que sua atuação, exercendo raciocínios entre a teoria adquirida na faculdade e as realidades sociais de seus pacientes, 
devia-se aos estágios extracurriculares durante sua formação. Complementando, Goulart e Chiari (2010, p. 260) afirmam que "não há como realizar esta síntese sem o concurso ativo dos usuários, não há saber técnico que realize por si só este tipo de integração".

De acordo com pesquisa realizada por Dalmolin e colaboradores (2011), em relação ao significado do conceito de saúde para docentes profissionais da área da saúde, muitos profissionais não apresentaram o conceito de saúde bem definido. Houve interconexões entre a visão reducionista e a ampliada do conceito, salientando os momentos de confusão no processo saúde-doença. Para um resultado de grande relevância em relação às mudanças necessárias na estruturação da formação acadêmica, a teoria associada à realidade social dos sujeitos envolvidos é o que determinará a qualidade das ações em saúde.

O profissional FIl atuava constantemente de forma tecnicista, e as atividades propostas de forma ativa não foram associadas a movimentos funcionais, como atividades de vida diária (AVDs - relacionadas aos cuidados do indivíduo com seu próprio corpo e também mais complexas, que abrangem higiene pessoal e autocuidado, alimentação, vestuário, mobilidade e demais funções), trocas de posturas (aquisição e sustentação das posições deitado, sentado e em pé) e transferências como da cama para a cadeira de rodas e vice-versa. Esse profissional demonstrou falta de coerência entre seu discurso e sua atuação, pois disse considerar alguns aspectos sociais importantes durante os atendimentos, mas essas considerações não apareceram nas observações realizadas, em que tratava o sujeito somente como um corpo-objeto.

Nas observações do atendimento $\mathrm{O} 3$ do profissional FIl, em que a criança começava a chorar em função do desejo de brincar com objetos que se encontravam chaveados em um armário no local do atendimento, o profissional disse delicadamente:

Tu vens aqui deitar na cama para fazer os exercícios; depois que tu fizeres os exercícios, tu podes brincar.

O corpo é um dos 'objetos' que assumem valores simbólicos relevantes na atualidade. São necessárias reflexões acerca das concepções de corpo-sujeito, que significa autonomia e subjetividade; e corpo-objeto, manipulado e fragmentado por relações de poder e controle (Porto, Simões e Moreira, 2004).

Em relação ao corpo-sujeito, Schmidt (2003) expõe:

Pode-se dizer que não basta que o indivíduo fale corretamente se não tiver nada de seu a dizer, que caminhe adequadamente e com equilíbrio se não tiver socialmente aonde ir, e que não basta apresentar um movimento tônico perfeito se não estiver vinculado a uma ação significativa para esse sujeito (Schmidt, 2003, p. 38). 
Nesse sentido, Silva e colaboradores (2002, p. 116) destacam uma questão fundamental: "nem os profissionais podem ser reduzidos às suas competências técnicas e nem os usuários a passivos objetos de intervenção".

Pelo exposto, verificou-se a importância de os profissionais deterem conhecimentos sobre práticas de saúde humanizadas e comprometidas socialmente, a fim de oportunizar melhor qualidade de vida para as pessoas com deficiência física e colaborar com a construção de uma sociedade inclusiva.

A concepção de humanização da saúde. O termo 'humanização' entrou em discussão no Movimento da Reforma Sanitária, ocorrido nos anos 1970 e 1980, quando se iniciaram os questionamentos acerca do modelo assistencial vigente na saúde, centrado no médico, no biologicismo e nas práticas curativas.

Assim, humanizar em saúde é resgatar o respeito à vida humana, levando-se em conta as circunstâncias sociais, éticas, educacionais e psíquicas presentes em todo relacionamento humano... "É resgatar a importância dos aspectos emocionais, indissociáveis dos aspectos físicos na intervenção em saúde" (Brasil, 2001, p. 33).

O processo de reabilitação deve ser desenvolvido com ações e atividades significativas para o paciente, sempre direcionadas às suas necessidades, para que o indivíduo se sinta motivado durante a terapia/tratamento. Entende-se que a humanização retoma o respeito à vida humana, em dimensões que atingem as circunstâncias sociais, éticas, educacionais e psíquicas presentes em todo relacionamento humano, evitando a fragmentação do ser humano. O cuidado técnico-científico articulado ao acolhimento e ao respeito ao indivíduo é o principal aspecto que envolve e fundamenta a humanização.

A relação terapeuta/médico-paciente influencia a motivação em vários níveis. Para o sucesso do tratamento, o terapeuta/médico deve ser capaz de motivá-lo e estar receptivo aos esforços do paciente. O programa terapêutico deve manter o indivíduo motivado e o profissional deve considerar as metas dele na elaboração do planejamento terapêutico.

Nessa categoria, propõe-se discutir tais relações humanas, contemplando a atuação do profissional da saúde e as repercussões nos indivíduos que estão sob seus cuidados.

Ao se partir do questionamento sobre o entendimento dos profissionais a respeito do conceito de saúde, demonstraram-se incertezas e opiniões contraditórias:

Bem-estar, ser feliz, estar feliz independente da situação, isso é ter saúde e reflete diretamente em sua saúde física (FI1).

Ausência de doença. Eu acredito que a saúde é uma coisa muito mais ampla do que um simples caso do organismo. Pra mim é uma questão de saúde a criança 
estar com piolho, e se a criança não consegue se coçar? É uma questão social, pra mim é uma questão de moradia; se ela vai passar frio ou vai passar calor, é uma questão de saúde (...) o isolamento social, a questão das dificuldades de acessibilidade (...) então, o termo saúde acaba englobando muitas outras coisas, e que muitas vezes pro profissional de saúde fica muito confuso (FO1).

Na realidade, é um global de bem-estar, é muito amplo, é que muitos dos problemas de saúde não são necessariamente relacionados com uma doença, nesse sentido é importante entender esse contexto global (...) porque se você consegue investir em prevenção, em ter uma vida social mais ativa, você fica menos doente, mas é óbvio que a saúde isoladamente é o bem-estar físico e mental, mas ele vem junto com os aspectos sociais (ME1).

Pra mim é qualidade de vida, não é porque um paciente tem uma sequela que ele não tem saúde, penso sempre em funcionalidade (FI2).

Bem-estar geral, físico, psíquico, emocional. Ter saúde é estar bem em várias áreas, estar bem onde tu vives, onde tu estudas, onde convives (FO2).

Pensar em bem-estar na sua totalidade, todos os fatores sociais, psíquicos e físicos são importantes (ME2).

O significado de saúde não foi bem definido nos discursos dos profissionais, havendo muitos momentos de confusão e incertezas. Segundo Ayres (2005), o conceito clássico de saúde acaba refletindo um sentido abstrato, fazendo com que o profissional não consiga percebê-lo e incorporá-lo em suas atuações. Ao se pensar na perspectiva ampliada do conceito de saúde, a humanização nas ações dos profissionais concretiza-se na preservação da vida associada a novos padrões de qualidade impostos pela sociedade atual (Goulart e Chiari, 2010). Mas percebeu-se que, para os profissionais entrevistados, a saúde não era somente ausência de doença; com suas peculiaridades, eles expressavam uma visão do sujeito como um todo, além das questões biológicas.

Segundo os profissionais FOl e FI2, a concretização da humanização da saúde somente ocorrerá se os pacientes e seus familiares tiverem acesso a serviços básicos no SUS, como triagem com profissionais adequados para o encaminhamento precoce aos serviços de reabilitação; acesso a procedimentos médicos e tratamentos no período adequado para evitar agravamentos das sequelas/doenças; e a partir desses serviços, melhoria na relação médico/terapeuta-paciente. Para o profissional FOl, um grande número de pessoas com deficiência física iniciava o processo de reabilitação tardiamente, apresentando deformidades articulares e sequelas mais intensas, quando 
muitos desses problemas poderiam ser evitados com a indicação precoce. Segundo ele, a relação humanizada médico/terapeuta/paciente somente ocorrerá no momento em que esses serviços se tornarem acessíveis.

Acesso e acessibilidade são termos ambíguos. O grau de ajuste entre as características dos recursos de saúde e as características da população no processo de busca e obtenção de assistência básica conceitua a acessibilidade, que é entendida por permitir a identificação de fatores que obstaculizam o cuidado nas dimensões organizacionais, geográficas, socioculturais e econômicas (Zampieri e Erdmann, 2010). O fato de o serviço ser acessível é condição básica para que qualquer política pública possa responder às necessidades sociais e gerar impacto positivo.

Sobre as necessidades de saúde da pessoa com deficiência física, a pesquisa realizada por Othero e Ayres (2012) demonstrou que a autonomia e a independência de pacientes atendidos pelo SUS foram aspectos muito valorizados, como também a prevenção e o diagnóstico precoce. Muitos pacientes relataram, inclusive, que tiveram seus diagnósticos tardios e consequentemente maiores incapacidades. Também se destacou como necessidade o (re)encontro com atividades significativas, salientando-se a retomada de valor, ação e interação com o contexto em que se vive, ligado à história individual, familiar e cultural de cada um (Othero e Ayres, 2012).

Nas instituições de reabilitação IRl e IR2, observaram-se, em alguns atendimentos, pacientes que se encontravam em situação de isolamento social em razão de procedimentos cirúrgicos ou tratamentos não realizados por burocracias e filas de espera no SUS. Tais procedimentos interferiam diretamente no processo de reabilitação, pois provocavam até situações de exaltação e desespero de familiares pela falta de acesso a direitos básicos para locomoção/deambulação e alimentação, como demonstrado na observação O4-FIl - quando houve o seguinte comentário de um pai indignado pelo fato de seu filho encontrar-se há um ano e meio à espera de um procedimento cirúrgico para a correção de uma luxação coxofemoral:7

Vou assaltar um banco para meu filho fazer a cirurgia e poder caminhar de novo. Vou preso, mas meu filho vai fazer a cirurgia.

Em 2004, foi instituída a Política Nacional de Humanização (PNH) 'HumanizaSUS' - com o propósito de promover a integralidade das ações de saúde. É um somatório de ofertas de apoio político e institucional, representado por quatro marcas: reduzir as filas e o tempo de espera com ampliação de acesso e atendimento acolhedor e resolutivo baseado em critérios de risco; assegurar que todos os usuários do SUS conheçam os profissionais que cuidam de sua saúde; garantir aos usuários o acesso às informações e à presença de acompanhante de sua livre escolha em todos os momentos do 
cuidado de sua saúde; e consolidar, nas unidades de saúde, a gestão participativa dos seus trabalhadores e usuários, assim como educação permanente aos trabalhadores de saúde (Brasil, 2004).

Segundo o profissional MEl, a humanização na medicina foi reduzida no decorrer dos anos, comparando-a com o ano de sua graduação, em 1984. Ele declarou que "essa humanização ocorria de forma mais natural", ou seja, a anamnese e o exame físico eram precondição para todos os atendimentos, e hoje "se vai direto para exames". O profissional disse que a sociedade mudou, não somente os profissionais da área da saúde, em que a tecnologia e a informatização geraram mudanças significativas nas relações pessoais, exigindo atitudes mais rápidas e objetivas dos profissionais. Maroun e Vieira (2008) afirmam que a tecnologia, com base na informação e na ciência, transformou o modo de pensar, produzir, consumir, comunicar e, consequentemente, alterou o modo de viver.

Em relação aos exames, Le Breton (2011) ressalta que eles mostram a "força e a fraqueza da medicina", pois a tecnologia contribui para diagnósticos mais precisos, porém intensifica o raciocínio de que a doença está na sua localização anatômica e funcional. O autor explica que os exames instigam o dualismo corpo-homem. Os diagnósticos são realizados não considerando a história do sujeito e o seu entorno social, mas a falha de uma função ou de um órgão, determinando a ruptura entre o corpo e o sujeito.

Ter como preocupação principal o ser humano em sua completude faz com que os profissionais da saúde tenham que refletir sobre a definição da própria área e sobre as técnicas desenvolvidas. Não é possível querer transformar as práticas de saúde se não for repensada a "estabilidade acrítica dos critérios considerados para avaliar e validar a correção ética e moral das ações na saúde" (Ayres, 2005, p. 550).

O processo de humanizar baseia-se em atitudes simples de se disponibilizar para ouvir, trocar experiências e comparar seu processo histórico com o outro. A percepção do outro, suas relações, histórias de vida é que permitem a identidade humana e também o ato de repensar e refazer práticas em saúde.

\section{Considerações finais}

A concretização de ações mais humanizadas e propostas de formação que contemplem os aspectos inerentes à humanização dos serviços passa por diversos aspectos. É importante para a efetivação dessas propostas uma formação acadêmica em que esses princípios sejam considerados e, mais do que isso, que esses pressupostos sejam protagonistas no processo de formação profissional, juntamente com as questões técnicas. É essencial que 
haja equilíbrio entre a capacitação científica e a formação humanística, de modo a privilegiar uma visão abrangente e multifatorial de saúde, bem como a sensibilidade no processo de se lidar com a realidade psicossocial das pessoas com deficiência física em processo de reabilitação.

$\mathrm{Na}$ análise das informações, verificaram-se salientes divergências entre os discursos e as atuações profissionais, pois foram mencionados fatores socioculturais importantes durante o processo de reabilitação que não eram condizentes com as práticas em questão.

Ficou explícito que os profissionais percebiam 'o paciente' como um sujeito envolvido por fatores socioculturais e que determinavam todas as ações e reações no processo saúde-doença. Mas em alguns casos, na prática, essas percepções não se concretizaram, pois 'o paciente' apareceu como um corpo-objeto fragmentado e submisso à manipulação. As práticas em saúde passaram a ser questionadas por se apresentarem mais objetivas e dispendiosas com a adoção das tecnologias modernas, ao mesmo tempo muito pouco humanizadas.

Um dos principais fatores mencionados foi a formação eminentemente tecnicista do profissional de saúde, que se sentia inseguro e despreparado para uma prática mais ampliada e humanizada. Os profissionais destacaram a carência de capacitação sociocultural durante suas formações acadêmicas, contribuindo para a falta de conexão das ações em saúde com a inclusão social e a humanização. Desse ponto de vista, surgiu a discussão sobre o que sustentava a qualidade do atendimento prestado durante a atuação profissional, em que a subjetividade individual aparecia como fio condutor, determinando concomitantemente a formação acadêmica e complementar.

No caso das instituições pesquisadas, constatou-se que as questões de acessibilidade e a utilização dos serviços do SUS estavam intimamente ligadas à inclusão social e ao processo de reabilitação, demonstrando claramente que a inclusão social de pessoas com deficiência física depende de vários setores interconectados, em que o papel da formação acadêmica e de efetivas políticas públicas em relação à saúde e à acessibilidade são fundamentais. Existem avanços importantes em relação a políticas públicas e legislação nesses setores, mas há falta de eficiência e eficácia. Um dos motivos é a carência de preparo dos profissionais envolvidos nas práticas em saúde.

A pesquisa que deu origem a este artigo apresentou limitações: a coleta de informações poderia ter sido realizada em mais instituições e ocorreu a falta de um instrumento que registrasse o conhecimento dos pais ou familiares para possibilitar maior complexidade dos resultados. Espera-se, no entanto, que ela traga subsídios empíricos e teóricos para se discutir o processo de inclusão social no âmbito da reabilitação, em que as práticas em saúde têm ocupado lugar de destaque nas atuais propostas para a construção de atuações humanizadas, no sentido de sua maior integralidade, efetividade e acesso. 


\title{
Colaboradores
}

\author{
Aline Missel desenvolveu todas as etapas da pesquisa e redigiu o artigo. \\ Cassia Cinara da Costa participou da revisão teórica. Gustavo Roese Sanfelice \\ foi o orientador da dissertação e participou da elaboração do artigo.
}

\begin{abstract}
Resumen El objetivo fue investigar percepciones y actuaciones de profesionales del área de la salud que actúan en instituciones de rehabilitación con personas portadoras de deficiencia física, en los aspectos relativos a la inclusión social, humanización de la salud y formación académica. Se realizó una investigación cualitativa y descriptiva, utilizando observaciones y entrevistas semiestructuradas como instrumentos de recolección de datos. En base a los datos recolectados, se originaron tres categorías: aspectos sociales del sujeto; actuación y conocimiento en relación a la inclusión social y formación; y concepción de humanización de la salud. Se han observado la complejidad de la rehabilitación de personas con deficiencia física y la identificación de obstáculos que deben transponerse, como dificultades para el acceso adecuado y precoz a los servicios del Sistema Único de Salud; falta de efectividad y eficacia de las políticas públicas y legislación con relación a la salud y a la accesibilidad; y carencia en capacitación sociocultural y humanizada de los profesionales involucrados. Concluimos que el papel de la formación académica y el de políticas públicas efectivas relacionadas con la salud y la accesibilidad son fundamentales para la inclusión social de personas con deficiencia física, pues se trata de aspecto interconectados, que necesita trabajo intersectorial para asegurar asistencia rehabilitadora de calidad.
\end{abstract}

Palabras clave personas con deficiencia; rehabilitación; socialización; humanización de la asistencia.

\section{Notas}

1 Clínica Multifisio, Tapes, Rio Grande do Sul, Brasil.

$<$ aline_missel@yahoo.com.br>

Correspondência: Rua Castilho Inácio Barcelos, 398, CEP 94010-450, Oriço, Gravataí, Rio Grande do Sul, Brasil.

2 Universidade Feevale, Faculdade de Fisioterapia, Novo Hamburgo, Rio Grande do Sul, Brasil.

<cassiac@feevale.br>

3 Universidade Feevale, Programa de Pós-Graduação em Diversidade Cultural e Inclusão Social, Novo Hamburgo, Rio Grande do Sul, Brasil.

<sanfeliceg@feevale.br> 
4 Atraso no DNPM: quando uma criança não adquire as tarefas desenvolvimentais referentes à sua faixa etária e não há um diagnóstico específico ou qualquer condição aparente que explique tal situação (Silva e Albuquerque, 2011).

5 A Lei de Cotas (lei n. 8213/1991), em seu artigo 93, estabelece que “a empresa com cem ou mais funcionários está obrigada a preencher de dois a cinco por cento dos seus cargos com beneficiários reabilitados ou pessoas com deficiência $(\ldots)^{\prime \prime}$.

6 Em razão de distúrbios no processo de deglutição, até uma pequena quantidade de líquido pode ser aspirado pelos pulmões e ocasionar pneumonias aspirativas, chegando a acarretar complicações sérias de saúde. Para evitar essas complicações, é indicado pelo médico, nutricionista ou fonoaudiólogo o produto chamado espessante, que transforma os alimentos em consistência de 'purê'.

7 É a articulação do quadril. Sua luxação leva a dores intensas, à mobilização da articulação e ao apoio do membro inferior afetado, gerando prejuízos para a deambulação do indivíduo.

\section{Referências}

ABRAHÃO, Ana L.; MARTINS, Carla M; GEISLER, Adriana. O sujeito na literatura acadêmica sobre gestão em saúde: notas para a questão da autonomia. Ciência \& Saúde Coletiva, Rio de Janeiro, v. 13, n. 1, p. 247-257, 2008.

AMORIM, Suely T. S. P.; MOREIRA, Herivelto; CARRARO, Telma E. A formação de pediatras e nutricionistas: a dimensão humana. Revista de Nutrição, Campinas, v. 14, n. 2, p. 111-118, 2001.

AYRES, José R. C. M. Hermenêutica e humanização das práticas de saúde. Ciência \& Saúde Coletiva, Rio de Janeiro, v. 10, n. 3, p. 549-560, 2005.

BARDIN, Laurence. Análise de conteúdo. 3. ed. São Paulo: Almedina, 2011.

BRASIL. Ministério da Saúde. Secretaria Executiva. Núcleo Técnico da Política Nacional de Humanização. Humaniza SUS: Política Nacional de Humanização. Brasília, DF: Ministério da Saúde, 2004. Disponí- vel em: <http://bvsms.saude.gov.br/bvs/ publicacoes/humanizasus_2004.pdf $>$. Acesso em: 30 maio 2012.

BRASIL. Ministério da Saúde. Politica Nacional de Humanização. Brasília, DF: Ministério da Saúde, 2004. Disponível em: <http:// bvsms.saude.gov.br/bvs/publicacoes/ humanizasus_2004.pdf>. Acesso em: 4 jun. 2012.

BRASIL. Ministério da Saúde. Política Nacional de Saúde da Pessoa Portadora de Deficiência. Brasília, DF: Editora do Ministério da Saúde, 2010. Disponível em: <http://bvsms. saude.gov.br/bvs/publicacoes/politica_ nacional_pessoa_com_deficiencia.pdf $>$. Acesso em: 15 jun. 2012.

BRASIL. Presidência da República. Casa Civil. Lei n. 8.213, de 24 de julho de 1991. Dispõe sobre os Planos de Benefícios da Previdência Social e dá outras providências. Diário Oficial da União, Brasília, DF, 25 jul. 1991. Disponível em: <www.planalto.gov.br/ccivil_03/ leis/L8213cons.htm>. Acesso em: 30 abr. 2013. 
CAMPOS, Claudinei J. G. Método de análise de conteúdo: ferramenta para a análise de dados qualitativos no campo da saúde. Revista Brasileira de Enfermagem, Brasília, v. 57, n. 5, p. 611-614, 2004.

DALMOLIN, Barbara B. et al. Significados do conceito de saúde na perspectiva de docentes da área da saúde. Escola Anna Nery Revista de Enfermagem, Rio de Janeiro, v. 15, n. 2, p. 389-394, jun. 2011.

DOUGLAS, Mary. Como as instituições pensam. São Paulo: EdUSP, 1998.

DUARTE, Teresa. A possibilidade da investigação a 3: reflexões sobre a triangulação (metodológica). Disponível em: <http://cies. iscte-iul.pt/destaques/documents/CIES-WP60_ Duarte_002.pdf>. Acesso em: 20 jan. 2013.

FARIAS, Norma; BUCHALLA, Cassia M. A classificação internacional de funcionalidade, incapacidade e saúde da Organização Mundial da Saúde: conceitos, usos e perspectivas. Revista Brasileira de Epidemiologia, São Paulo, v. 8, n. 2, p. 187-193, 2005.

FERREIRA, Jaqueline. Consulta médica como drama social. Cadernos de Saúde Coletiva, Rio de Janeiro, v. 19, n. 2, p. 215-224, 2011.

FRANÇA, Marcio P. et al. Aquisição da linguagem oral: relação e risco para a linguagem escrita. Arquivos de Neuro-Psiquiatria, São Paulo, v. 62, n. 2, p. 469-472, 2004.

GOFFMAN, Erving. Estigma: notas sobre a manipulação da identidade deteriorada. Rio de Janeiro: Guanabara Koogan, 1988.

GOULART, Barbara N. G; CHIARI, Basília. M. Humanização das práticas do profissional de saúde: contribuições para reflexão. Ciência \& Saúde Coletiva, Rio de Janeiro, v. 15, n. 1, p. 255-268, 2010.

INSTITUTO BRASILEIRO DE GEOGRAFIA E ESTATÍSTICA (IBGE). Perfil das deficiências nos domicílios no Brasil. Brasília: IBGE, 2010. Disponível em: <http://biblioteca.ibge. gov.br/visualizacao/periodicos/94/cd_2010_ religiao_deficiencia.pdf $>$. Acesso em: 5 maio 2012.

LE BRETON, David. Antropologia do corpo e modernidade. Petrópolis: Vozes, 2011.

MAROUN, Kalyla; VIEIRA, Valdo. Corpo: uma mercadoria na pós-modernidade. Psicologia em Revista, Belo Horizonte, v. 14, n. 2, p. 171-186, dez. 2008.

ORGANIZAÇÃO DAS NAÇÕES UNIDAS (ONU). A ONU e as pessoas com deficiência. 2011. Disponível em: < https://nacoesunidas.org/ acao/pessoas-com-deficiencia $>$. Acesso em: 30 out. 2013.

ORGANIZAÇÃO DAS NAÇÕES UNIDAS (ONU). Convenção Internacional dos Direitos da Pessoa com Deficiência. 2006. Disponível em: $<$ www.acessibilidade.net/convencao.php $>$. Acesso em: 20 jun. 2012.

OTHERO, Marília B.; AYRES, José R. C. M. Necessidades de saúde da pessoa com deficiência: a perspectiva dos sujeitos por meio de histórias de vida. Interface: Comunicação, Saúde e Educação, Botucatu, v. 16, n. 40, p. 219-234, 2012.

PEREIRA, Luciane M. F. et al. Acessibilidade e crianças com paralisia cerebral: a visão do cuidador primário. Fisioterapia e Movimento, Curitiba, v. 24, n. 2, p. 299-306, 2011.

PORTO, Eliane; SIMÕES, Regina; MOREIRA, Wey W. Corporeidade e ação profissional na reabilitação: (des)encontros. Revista Brasileira de Ciências do Esporte, Campinas, v. 25, n. 3, p. 101-116, 2004.

PUPO FILHO, Ruy A. Interagindo com a criança especial. In: SOUZA, Angela M. C. (org.). A criança especial: temas médicos, educativos e sociais. São Paulo: Roca, 2003. p. 1-5.

RIBEIRO, Clécio. R. Proposta psicossocial para pacientes com enfermidades graves ou terminais. Revista Bioética, Rio de Janeiro, v. 5, n. 2, p. 819-831, 2011. 
SCHMIDT, A. P. A equipe terapêutica e a criança especial. In: SOUZA, Angela M. C. (org.). A criança especial: temas médicos, educativos e sociais. São Paulo: Roca, 2003. p. 37-38.

SILVA, Elisabete. M.; ALBUQUERQUE, Cristina. P. Atraso do desenvolvimento: a imprecisão de um termo. Psicologia: Saúde \& Doenças, Lisboa, v. 12, n. 1, p. 19-39, 2011.

SILVA, Neide. E. K. et al. Limites do trabalho multiprofissional: estudo de caso dos centros de referência para DST/Aids. Revista de Saúde Pública, São Paulo, v. 36, n. 4, p. 108-116, 2002.

SIMÕES, Cristiana. A. Reabilitação de crianças com deficiência motora pelo Sistema Único de Saúde da Bahia: desafios e perspectivas. 144 f. Dissertação (Mestrado) - Universidade Católica do Salvador, Salvador, 2008.

SIQUEIRA, Sueli. O trabalho e a pesquisa científica na construção do conhecimento. 2. ed. Governador Valadares: Univale, 2005.
SIROTA, Régine. Emergência de uma sociologia da infância: evolução do objeto e do olhar. Cadernos de Pesquisa, São Paulo, v. 1, n. 112, p. 7-31, 2001.

VILELA, Elaine M.; MENDES, Iranilde. J. M. Interdisciplinaridade e saúde: estudo bibliográfico. Revista Latino-Americana de Enfermagem, São Paulo, v. 11, n. 4, p. 525-531, 2003.

ZAMPIERI, Maria F. M.; ERDMANN, Alacoque L. Cuidado humanizado no pré-natal: um olhar para além das divergências e convergências. Revista Brasileira de Saúde Materno Infantil, Recife, v. 10, n. 3, p. 359-367, 2010 .

Recebido em 05/01/2015

Aprovado em 13/05/2016 